\title{
The Electronic Factor in Alkane Oxidation
}

\section{Catalysis}

\author{
Maik Eichelbaum, ${ }^{*} \dagger, \ddagger$ Michael Hävecker, ${ }^{\dagger}, \Phi$ Christian Heine, ${ }^{\dagger}$ Anna Maria \\ Wernbacher, ${ }^{\dagger}$ Frank Rosowski $^{\ddagger}, \S$ Annette Trunschke, $^{\dagger}$ and Robert Schlögl ${ }^{\dagger}$ \\ ${ }^{\dagger}$ Department of Inorganic Chemistry, Fritz-Haber-Institut der Max-Planck-Gesellschaft, \\ Faradayweg 4-6, 14195 Berlin, Germany, ${ }^{\ddagger}$ BasCat, UniCat BASF JointLab, TU Berlin, \\ Marchstraße 6, 10587 Berlin, Germany, ${ }^{\top}$ Helmholtz Centre Berlin / BESSY II, Solar \\ Energy Research, Albert-Einstein-Straße 15, 12489 Berlin, Germany, and ${ }^{\S}$ Process \\ Research and Chemical Engineering, Heterogeneous Catalysis, BASF SE, \\ Carl-Bosch-Straße 38, 67056 Ludwigshafen, Germany \\ E-mail: me@fhi-berlin.mpg.de
}

Phone: +49 (0)30 84134566. Fax: +49 (0)30 84134405

\begin{abstract}
We are addressing the fundamental question, if semiconductor physics concepts can be applied to describe the working mode of heterogeneous oxidation catalysts and if they can be even used to discriminate between selective and unselective reaction pathways. By the application of near-ambient pressure X-ray photoelectron spectroscopy it could be shown exemplarily for the oxidation of n-butane to maleic anhydride on the
\end{abstract}

* To whom correspondence should be addressed

${ }^{\dagger}$ Fritz-Haber-Institut

${ }^{\ddagger}$ BasCat, UniCat BASF JointLab

"Helmholtz Centre Berlin / BESSY II

$\S$ BASF SE 
highly selective catalyst vanadyl pyrophosphate and the moderately selective MoVTeNbOx M1 phase that the catalysts act like semiconducting gas sensors with a dynamic bulk-surface charge transfer, as indicated by the gas phase response of the work function, electron affinity and the surface potential barrier. In contrast, only a minor influence of the gas phase on the semiconducting properties and hence no dynamic surface potential barrier was monitored for the total oxidation catalyst $\mathrm{V}_{2} \mathrm{O}_{5}$. The surface potential barrier is hence suggested as descriptor for selectivity.

Since the middle of the last century, semiconductor physics concepts have been used to explain the working mode of selective alkane and alkene oxidation catalysts. ${ }^{1-7}$ The vision was - and still is - to predict the catalytic activity and selectivity of materials in different reactions on the basis of their electronic structure (the so-called "electronic factor"). In semiconductor theory the difference between the Fermi potential of the semiconducting catalyst and the redox potential of adsorbates creates a driving force for charge transfer across the bulk-surface-adsorbate interface. ${ }^{5,8}$ This charge transfer generates a potential gradient and hence electric field between surface and bulk and can induce conductive channels with current rectifying properties like in a p-n junction diode. ${ }^{9}$ The height of this surface potential barrier, which charge carriers have to overcome to move between bulk and surface, could have a significant kinetic impact on the oxidation reaction on the surface and the activation of oxygen. ${ }^{5}$ The surface barrier height under steady-state reaction conditions could hence be a descriptor for the catalytic performance of oxidation catalysts. However, it has not proven so far that oxidation catalysts act indeed like semiconducting gas sensors with the formation of a surface potential barrier controlled by the gas phase.

Understanding the working mode of vanadyl pyrophosphate (VPP), which is the commercial catalyst for the oxidation of n-butane to maleic anhydride. ${ }^{10-14}$ is of general interest, since it is a benchmark system in selective oxidation catalysis, ${ }^{15-21}$ representing one of the most important class of heterogeneously catalyzed reactions in context of the dawning raw material change. ${ }^{22}$ Due to the increasing conductivity in air and decreasing conductivity in 
n-butane containing gas mixtures, VPP was identified as p-type semiconductor with electron holes as majority charge carriers. ${ }^{10-14,23-26}$ However, the conductivity response alone is not a sufficient descriptor for selectivity, since vanadium(V) oxide exhibits as well a reversible conductivity response under reaction conditions, ${ }^{27}$ but catalyzes only the total oxidation of n-butane to $\mathrm{CO}$ and $\mathrm{CO}_{2}$.

In our contribution we report on the successful application of near-ambient pressure X-ray photoelectron spectroscopy (NAP-XPS) to investigate the influence of the reactive gas phase on the surface potential barrier of VPP under catalytic n-butane oxidation conditions with proven maleic anhydride production. The results show that the transfer of charge carriers between the bulk catalyst and the surface can be explained by - and are thus the first experimental proof for - the previously only theoretically proposed semiconductor catalyst concepts of Boudart, ${ }^{1}$ Schwab, ${ }^{2}$ Volkenshtein, ${ }^{3}$ and Morrison. ${ }^{4,5}$ We compare these results with the electronic response of the unselective oxidation catalyst $\mathrm{V}_{2} \mathrm{O}_{5}$ and the moderately selective catalyst $\mathrm{MoVTeNbO}_{x}$ (orthorhombic M1 phase) in order to identify a general concept that can explain selectivity.

We investigated the polycrystalline catalyst VPP with NAP-XPS at $25 \mathrm{~Pa}$ and $400^{\circ} \mathrm{C}$ in 1:10 n-butane/oxygen $\left(\mathrm{C}_{4} \mathrm{H}_{10} / \mathrm{O}_{2}\right), 1: 10$ helium/oxygen $\left(\mathrm{O}_{2}\right)$ and 1:10 n-butane/helium $\left(\mathrm{C}_{4} \mathrm{H}_{10}\right)$ mixtures, according to the protocol described in the Supporting Information. The studied catalyst produces in a fixed-bed flow-through reactor at 1 bar maleic anhydride with a selectivity between 70 and $80 \% .{ }^{24,25}$ In semiconductor physics, a gas-phase dependent surface potential barrier (band bending) and hence a charge carrier exchange between bulk and surface can be evidenced, if the work function, the valence band and all core level binding energies are consistently shifted by the same absolute value upon adsorbing different gases (cf. Figure S2, in the Supporting Information). ${ }^{8}$ Thus, we measured the dependence of the valence band onset, V3d valence state, work function (by measuring the secondary electron cutoff), as well as of the O1s, V2p, and P2p core levels on the different gas mixtures. Figure 1 shows XP spectra at high (secondary electron cutoff) and low binding energies (valence band) 
in the three different gas atmospheres. The peak close to the valence band at about 2-2.5 eV below the Fermi level $(0 \mathrm{eV})$ is assigned to an occupied vanadium $3 \mathrm{~d}$ state. Upon changing the applied gas mixture, the secondary electron cutoff, valence band onset, and V3d state shift to higher binding energies under reducing $\mathrm{C}_{4} \mathrm{H}_{10}$ conditions, while only slight differences can be recognized between spectra recorded in $\mathrm{C}_{4} \mathrm{H}_{10} / \mathrm{O}_{2}$ and $\mathrm{O}_{2}$ (Figure 1). Moreover, the peak intensity of the V3d state increases under $\mathrm{C}_{4} \mathrm{H}_{10}$ conditions, indicating a larger electron occupation of this valence state and hence reduction of the catalyst phase.

Figure 2 summarizes the observed changes of the work function, V3d state, vanadium oxidation state (deduced from $\mathrm{V} 2 \mathrm{p}_{3 / 2}$ core level) and electron affinity. The binding energy shifts of the core levels V2 $\mathrm{p}_{3 / 2}, \mathrm{O} 1 \mathrm{~s}$, and P2p are depicted in Figure S1 (Supporting Information). The V3d state is reversibly shifted by up to $540 \mathrm{meV}$, while the measured core levels are reversibly shifted by about $500 \mathrm{meV}$ between oxidizing $\mathrm{O}_{2}$ and reducing $\mathrm{C}_{4} \mathrm{H}_{10}$ conditions. This consistent behavior is a strong indication for a bulk-surface charge transfer accompanied by the formation of a sub-surface space charge region and a gas-phase dependent surface potential barrier (i.e. band bending). The proton-transfer reaction mass spectrometry (PTR-MS) signal at $\mathrm{m} / \mathrm{z}=99$ (mass of protonated maleic anhydride), recorded during the applied experimental protocol, proves that under $\mathrm{C}_{4} \mathrm{H}_{10} / \mathrm{O}_{2}$ reaction conditions maleic anhydride is produced and that the catalyst was indeed studied under catalytic operation conditions (Figure 2a).

The work function $\Phi$ is deduced by calculating the difference between the excitation energy and the energy value at half maximum of the secondary electron cutoff. The measured work functions for VPP range between $6.94 \mathrm{eV}$ in $\mathrm{O}_{2}$ and $6.7 \mathrm{eV}$ in $\mathrm{C}_{4} \mathrm{H}_{10}$ (Figure 2b). These values are very well comparable with the work function of the binary oxide $\mathrm{V}_{2} \mathrm{O}_{5}$ $(\phi=7.0 \mathrm{eV}) .{ }^{28}$ As mentioned earlier, a pure Fermi level pinning to the adsorbate induced surface states energy can be evidenced, if the work function and all valence and core level binding energies are consistently shifted by the same absolute value upon adsorbing different gases. However, the total changes of $\Phi$ are with up to $240 \mathrm{meV}$ significantly smaller than 
observed for the valence and core levels. Adsorbates on a surface of a semiconductor cannot only induce surface states causing band bending, but they can also affect the surface dipolar structure, ${ }^{8}$ which would be indicated by a modified surface electron affinity (Figure S2, in the Supporting Information). Since the energy shifts in the different gas mixtures between work function and valence/core level binding energies are different, the adsorbates have modified both surface dipoles and surface states. ${ }^{8}$ Thus, from this energy shift difference the electron affinity change $\Delta \chi$ induced by the adsorbates can be calculated (Figure $2 \mathrm{e}$ ). Moreover, the average vanadium oxidation state is with nearly 4.4 highest in $\mathrm{O}_{2}$, and with 4.0 lowest in $\mathrm{C}_{4} \mathrm{H}_{10}$ (Figure $2 \mathrm{~d}$ ). Since the core level spectra were measured at a kinetic energy corresponding to a mean free electron path of $0.7 \mathrm{~nm}$ and hence comprehend basically the very first surface layer(s), the surface of VPP is obviously oxidized under $\mathrm{O}_{2}$ and $\mathrm{C}_{4} \mathrm{H}_{10} / \mathrm{O}_{2}$ conditions in comparison to the VPP bulk vanadium oxidation state of 4.0.

The obtained results for the electronic response of VPP in the different gas mixtures are schematically summarized in a simplified band diagram (Figure 3). Notably, the electronic structure of the catalyst has not necessarily to be described by delocalized bands. If FermiDirac electron statistics can be applied and electron or electron hole conduction can be described by a hopping mechanism of charge carriers between localized molecular orbitals, a similar double layer formation with an electric field between surface and bulk will form and similar binding energy shifts of the valence and core levels can be expected.

Band bending and the surface potential barrier are induced by the pinning of the Fermi potential to the surface state potential, being modified by the gas phase chemical potential. The surface states could be identified by a $\mathrm{V}^{4+} / \mathrm{V}^{5+}$ redox couple on the surface. In this case, the Fermi level $\left(E_{F}\right)$ pinning is given by: ${ }^{5}$

$$
E_{F}(\text { with surface states })=E_{t}+k T \ln \frac{\left[\mathrm{V}^{4+}\right]}{\left[\mathrm{V}^{5+}\right]}
$$


$E_{t}$ could be approximated by the redox potential of the $\mathrm{V}^{4+} / \mathrm{V}^{5+}$ couple. The suggested relationship between surface barrier (band bending) and vanadium oxidation state is strongly supported by the simultaneously observed modulation of the average vanadium oxidation state (Figure 2d) and intensity of the V3d valence state (Figure 1). The surface potential barrier height $q V_{B}$ is the difference between the (hypothetical) Fermi level of the catalyst without surface states and the Fermi level of the catalyst with surface states modified by the gas phase as defined in eq 1 :

$$
\left.q V_{B}=E_{F} \text { (without surface states, flatband }\right)-E_{F} \text { (with surface states) }
$$

Many recent surface sensitive experiments under reaction conditions indicate that the catalyst is terminated by a 2 -dimensional vanadium $(\mathrm{IV}, \mathrm{V})$ oxide layer deviating significantly from the bulk crystal structure. ${ }^{24,25,29-31}$ Hence, the proposed $\mathrm{V}^{4+} / \mathrm{V}^{5+}$ surface states should be a part of this termination layer, or in semiconductor physics nomenclature,${ }^{5}$ are extrinsic surface states from a surface termination with broken translational symmetry, as has been already suggested by Boudart with his concept of a "defect one-phase surface system". ${ }^{1}$

As indicated by eq 1 and eq 2 , a high $\mathrm{V}^{5+} / \mathrm{V}^{4+}$ ratio can increase the surface barrier height $q V_{B}$ to such values, that the bulk-surface electron transport is impeded. Under such conditions, also the activation (reduction) of gas phase oxygen is strongly limited. As a consequence, the surface barrier confines the concentration of activated oxygen on the surface. Since an accumulation of oxygen will cause the total oxidation of the desired oxygenate to $\mathrm{CO}_{x}$, the surface potential barrier could control the catalytic selectivity.

In order to check the suggested relationship between surface barrier and selectivity, the unselective (i.e. without selectivity to maleic anhydride, but only to $\mathrm{CO}$ and $\mathrm{CO}_{2}$ ) catalyst vanadium(V) oxide was investigated by NAP-XPS. Under strongly oxidizing conditions in $\mathrm{O}_{2}$ a maximum work function of $7.00 \mathrm{eV}$ and a vanadium oxidation state of 4.9 is measured 
(Figure 4a). A reduction to an average vanadium oxidation state of 4.8 is observed in $\mathrm{C}_{4} \mathrm{H}_{10}$ (Figure $4 \mathrm{a}$ ). However, the work function is at the same time only slightly reduced to $6.96 \mathrm{eV}$. Moreover, the valence band onset is only weakly changed from $2.18 \mathrm{eV}\left(\mathrm{O}_{2}\right)$ to $2.22 \mathrm{eV}\left(\mathrm{C}_{4} \mathrm{H}_{10}\right)$. Although all these changes are reversible and hence real, they are much less pronounced than in VPP. As a consequence, the effect of the gases on the surface barrier is small. This can be explained by the much higher conductivity of $\mathrm{V}_{2} \mathrm{O}_{5},{ }^{27}$ where the depletion of electrons in the bulk by charge transfer between catalyst and gas phase is negligible compared to its high charge carrier density. Hence, no surface potential barrier due to a significant charge depletion in the sub-surface space charge region is formed or modified. This has the consequence that the oxygen activation is not limited by the surface barrier, which could indeed explain the observed total oxidation of n-butane to $\mathrm{CO}_{x}$.

In addition, we investigated an alternative selective n-butane oxidation catalyst, the orthorhombic $\mathrm{MoVTeNbO}_{x} \mathrm{M} 1$ phase, with a maleic anhydride selectivity of more than $40 \% .{ }^{32}$ The gas phase conditions were shifted between 1:2 mixtures of ethane $/ \mathrm{O}_{2}$ and n-butane $/ \mathrm{O}_{2}$ to mimic a more oxidizing and reducing atmosphere, respectively, since the catalyst is not stable in pure $\mathrm{O}_{2}$ or n-butane at reduced pressures. The vanadium oxidation state changed (reversibly) from about 4.6 to 4.5 (oxidation states of the other metal ions remained constant ${ }^{32}$ ), the work function shifted by $200 \mathrm{meV}$ and the valence band onset by about $70 \mathrm{meV}$ (Figure 4b), indicating a gas-phase dependent surface potential barrier and a change of the surface electron affinity by about $130 \mathrm{meV}$. Since the shifts are significantly larger than observed for $\mathrm{V}_{2} \mathrm{O}_{5}$, despite the milder changes in the oxidation/reduction conditions, these results are in line with the intermediate selectivity of this catalyst and support the concept of a surface barrier mediated bulk-surface charge transfer influencing the catalytic selectivity. The strong surface restructuring indicated by the electron affinity change observed for both selective catalysts is in line with the idea that the active surface is formed in the presence of reaction gases as generally observed in selective alkane oxidation catalysis. ${ }^{33}$

In conclusion, NAP-XPS experiments prove that the selective alkane oxidation catalysts 
VPP and $\mathrm{MoVTeNbO}_{x}$ M1 phase act like semiconducting gas sensors with a gas phase dependent surface potential barrier. These results can hence be considered as an experimental proof for the early semiconductor catalyst concepts of Boudart, ${ }^{1}$ Schwab, ${ }^{2}$ and Volkenshtein. ${ }^{3}$ The formation of a dynamic surface potential barrier could give a rational description for catalytic selectivity in oxidation reactions. Within this concept the surface barrier controls the transfer of charge carriers between bulk and surface, and hence the activation of oxygen on the surface. This interpretation is strongly supported by experiments on the unselective catalyst $\mathrm{V}_{2} \mathrm{O}_{5}$, where the effect of the gas phase on the surface potential barrier was minute.

\section{Acknowledgement}

The work was conducted in the framework of the BasCat collaboration between BASF SE, TU Berlin, FHI and the cluster of excellence Unicat. The HZB staff is acknowledged for their continual support of the electron spectroscopy activities of the FHI at BESSY II.

\section{References}

(1) Boudart, M. J. Am. Chem. Soc. 1952, 74, 1531-1535.

(2) Schwab, G.-M. Angew. Chem. 1961, 73, 399-401.

(3) Volkenshtein, F. F. The Electronic Theory of Catalysis on Semiconductors; Pergamon Press, 1963.

(4) Morrison, S. R. J. Catal. 1974, 34, 462-478.

(5) Morrison, S. R. The Chemical Physics of Surfaces; Plenum Press, 1977.

(6) Haber, J.; Witko, M. J. Catal. 2003, 216, 416-424.

(7) Herrmann, J. M. Catal. Today 2006, 112, 73-77. 
(8) Mönch, W. J. Vac. Sci. Technol. B 1989, 7, 1216-1225.

(9) Lüth, H. Space Charge Layer; Springer Verlag, 2001; Chapter Electronic structure of Surfaces, pp $329-380$.

(10) Rouvet, F.; Herrmann, J. M.; Volta, J. C. J. Chem. Soc. Faraday Trans. 1994, 90, $1441-1448$.

(11) Herrmann, J. M.; Vernoux, P.; Bere, K. E.; Abon, M. J. Catal. 1997, 167, 106-117.

(12) Ait-Lachgar, K.; Tuel, A.; Brun, M.; Herrmann, J. M.; Krafft, J. M.; Martin, J. R.; Volta, J. C.; Abon, M. J. Catal. 1998, 1777, 224-230.

(13) Rihko-Struckmann, L. K.; Ye, Y.; Chalakov, L.; Suchorski, Y.; Weiss, H.; Sundmacher, K. Catal. Lett. 2006, 109, 89-96.

(14) Sartoni, L.; Delimitis, A.; Bartley, J. K.; Burrows, A.; Roussel, H.; Herrmann, J. M.; Volta, J. C.; Kiely, C. J.; Hutchings, G. J. J. Mater. Chem. 2006, 16, 4348-4360.

(15) Centi, G.; Trifiro, F.; Ebner, J. R.; Franchetti, V. M. Chem. Rev. 1988, 88, 55-80.

(16) Centi, G. Catal. Today 1993, 16, 5-26.

(17) Volta, J. C. Comptes Rendus De L Academie Des Sciences Serie Ii Fascicule C-chimie 2000, 3, 717-723.

(18) Grasselli, R. K. Top. Catal. 2001, 15, 93-101.

(19) Ballarini, N.; Cavani, F.; Cortelli, C.; Ligi, S.; Pierelli, F.; Trifiro, F.; Fumagalli, C.; Mazzoni, G.; Monti, T. Top. Catal. 2006, 38, 147-156.

(20) Dummer, N. F.; Bartley, J. K.; Hutchings, G. J. Adv. Catal. 2011, 54, 189-247.

(21) Védrine, J. C.; Hutchings, G. J.; Kiely, C. J. Catal. Today 2013, 217, 57-64.

(22) Cavani, F. Catal. Today 2010, 157, 8-15. 
(23) Eichelbaum, M.; Stößer, R.; Karpov, A.; Dobner, C.-K.; Rosowski, F.; Trunschke, A.; Schlögl, R. Phys. Chem. Chem. Phys. 2012, 14, 1302-1312.

(24) Eichelbaum, M.; Hävecker, M.; Heine, C.; Karpov, A.; Dobner, C. K.; Rosowski, F.; Trunschke, A.; Schlögl, R. Angew. Chem. Int. Ed. 2012, 51, 6246-6250.

(25) Eichelbaum, M.; Hävecker, M.; Heine, C.; Karpov, A.; Dobner, C. K.; Rosowski, F.; Trunschke, A.; Schlögl, R. Angew. Chem. 2012, 124, 6350-6354.

(26) Eichelbaum, M.; Glaum, R.; Hävecker, M.; Wittich, K.; Heine, C.; Schwarz, H.; Dobner, C. K.; Welker-Nieuwoudt, C.; Trunschke, A.; Schlögl, R. ChemCatChem 2013, 5, $2318-2329$.

(27) Heine, C.; Girgsdies, F.; Trunschke, A.; Schlögl, R.; Eichelbaum, M. Appl. Phys. A: Mater. Sci. Process. 2013, 112, 289-296.

(28) Meyer, J.; Zilberberg, K.; Riedl, T.; Kahn, A. J. Appl. Phys. 2011, 110, 033710.

(29) Kleimenov, E.; Bluhm, H.; Hävecker, M.; Knop-Gericke, A.; Pestryakov, A.; Teschner, D.; Lopez-Sanchez, J. A.; Bartley, J. K.; Hutchings, G. J.; Schlögl, R. Surf. Sci. 2005, 575, 181-188.

(30) Hävecker, M.; Mayer, R. W.; Knop-Gericke, A.; Bluhm, H.; Kleimenov, E.; Liskowski, A.; Su, D.; Follath, R.; Requejo, F. G.; Ogletree, D. F.; Salmeron, M.; Lopez-Sanchez, J. A.; Bartley, J. K.; Hutchings, G. J.; Schlögl, R. J. Phys. Chem. B 2003, 107, 4587-4596.

(31) Bluhm, H.; Hävecker, M.; Kleimenov, E.; Knop-Gericke, A.; Liskowski, A.; Schlögl, R.; Su, D. S. Top. Catal. 2003, 23, 99-107.

(32) Heine, C.; Hävecker, M.; Sanchez-Sanchez, M.; Trunschke, A.; Schlögl, R.; Eichelbaum, M. . J. Phys. Chem. C 2013, 117, 26988-26997.

(33) Schlögl, R. Top. Catal. 2011, 54, 627-638. 


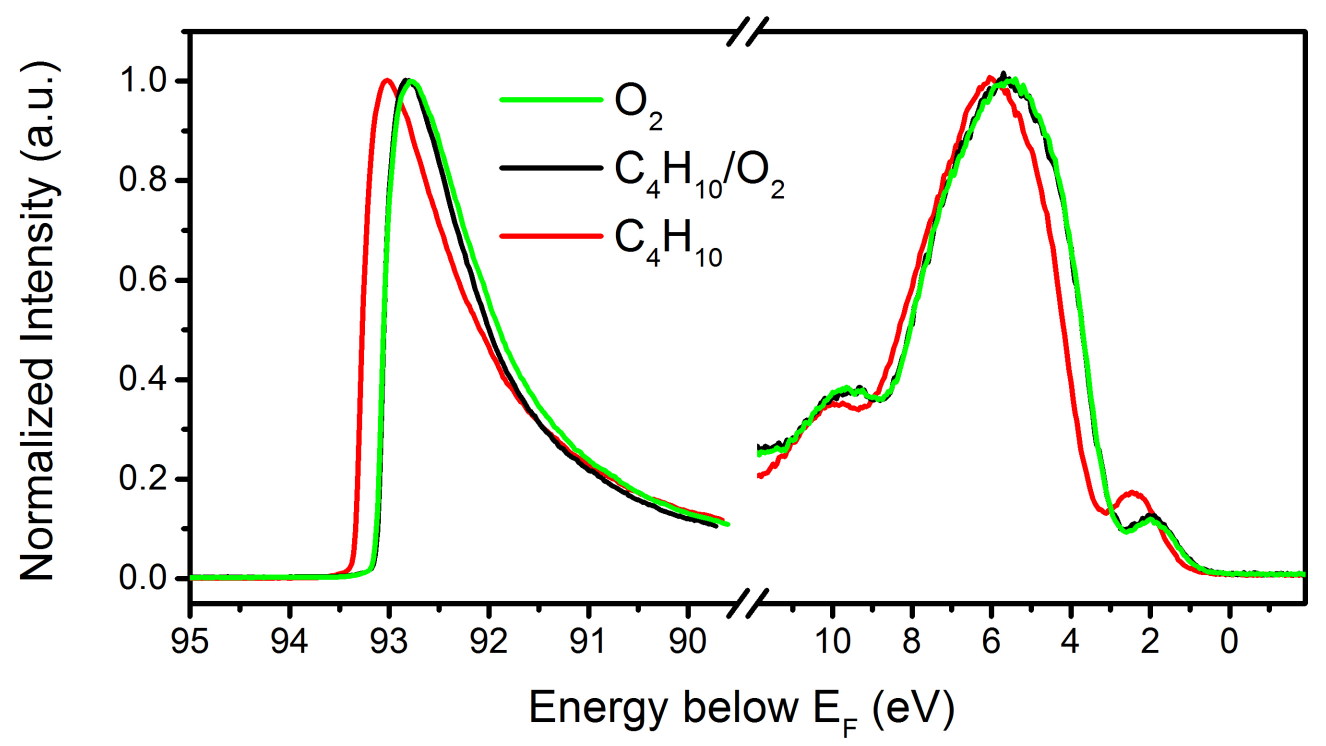

Figure 1: High (secondary electron cutoff; left) and low binding energy edge (valence band with V3d state at about $2 \mathrm{eV}$; right) of the XP spectra of VPP at $400^{\circ} \mathrm{C}$ under catalytic working $\left(\mathrm{C}_{4} \mathrm{H}_{10} / \mathrm{O}_{2}\right)$, oxidizing $\left(\mathrm{O}_{2}\right)$ and reducing conditions $\left(\mathrm{C}_{4} \mathrm{H}_{10}\right)$, respectively. The spectra were measured with an excitation energy of $100 \mathrm{eV}$. 


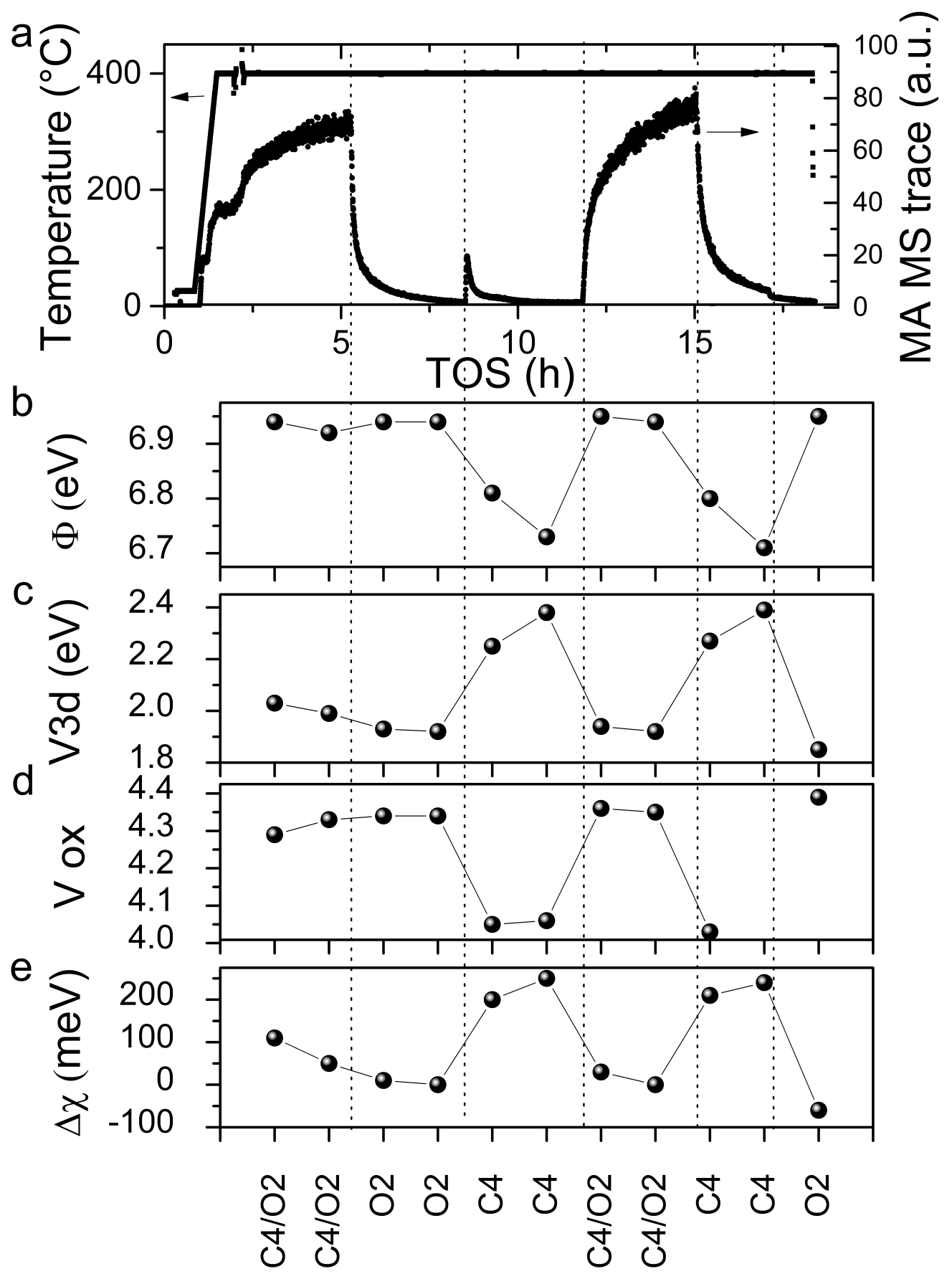

Conditions

Figure 2: a) PTR-MS trace of maleic anhydride (MA; protonated mass 99) during time on stream (TOS) under conditions indicated in the abscissa of e, b) work function $\Phi, c$ ) V3d valence state binding energy, $d$ ) average vanadium oxidation state ( $\mathrm{V}$ ox $)$ as deduced from the $V 2 \mathrm{p}_{3 / 2}$ spectra, and e) electron affinity change $\Delta \chi(\Delta \Phi-\Delta \mathrm{BE}(\mathrm{V} 3 \mathrm{~d})$, difference to 2 nd $\mathrm{O}_{2}$ condition) of $\mathrm{VPP}$ at $400^{\circ} \mathrm{C}$ in different gas mixtures. 


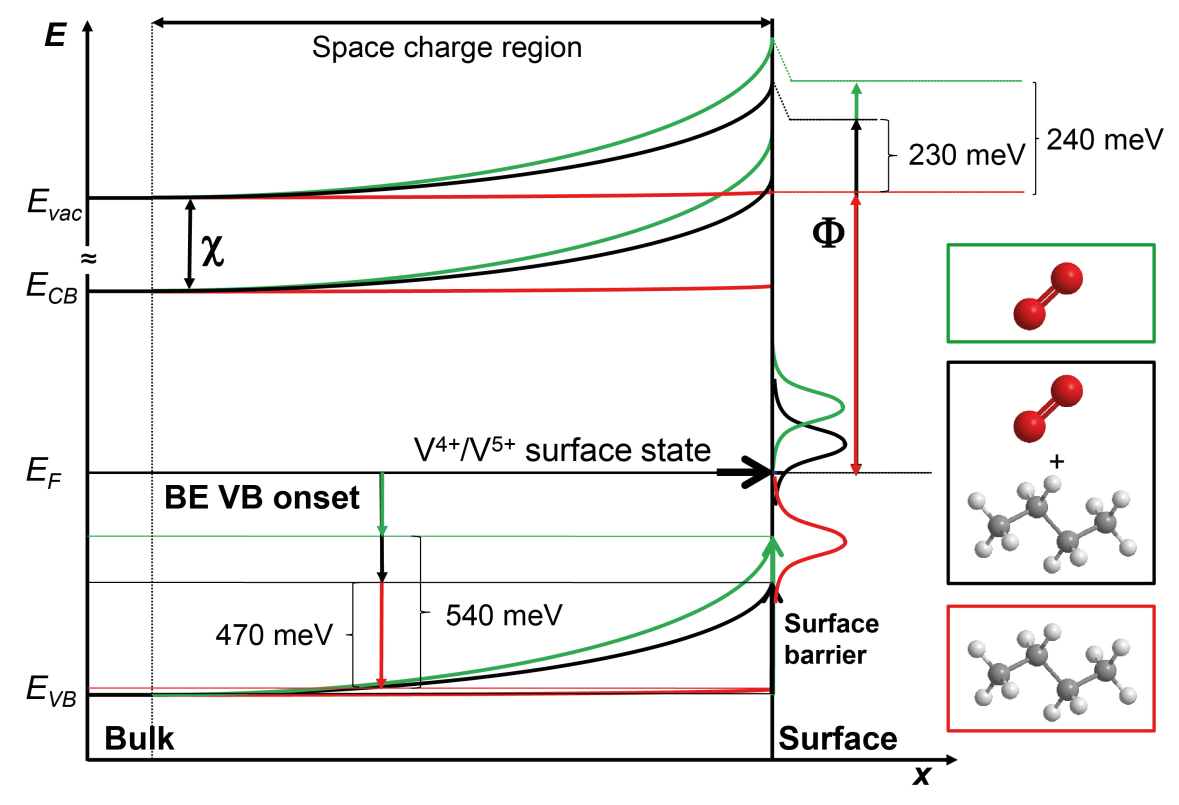

Figure 3: Schematic band diagram of VPP with experimentally obtained values for the binding energy (BE) shifts of the valence band (VB) onset and of the work function $\Phi$ measured in n-butane/helium (red), n-butane/oxygen (black), oxygen/helium (green). $E_{V B}$ : valence band onset, $E_{F}$ : Fermi level, $E_{C B}$ : conduction band minimum, $E_{v a c}$ : vacuum level, $\chi$ : electron affinity.
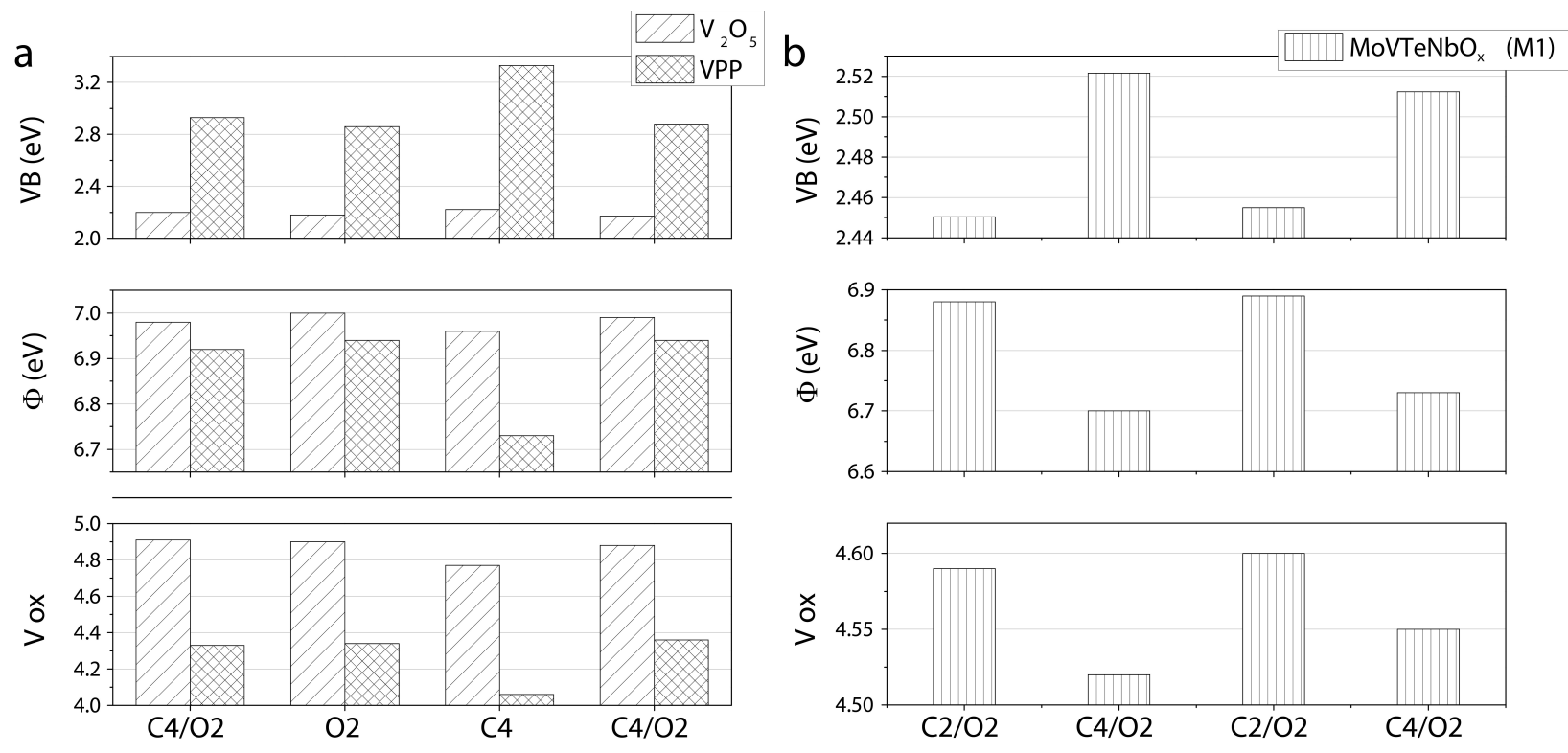

Figure 4: Valence band onset (VB), work function $\Phi$, and surface vanadium oxidation state (V ox) of $\mathrm{VPP}, \mathrm{V}_{2} \mathrm{O}_{5}$ (a) and $\mathrm{MoVTeNbO}_{x} \mathrm{M} 1$ phase (b) at $400^{\circ} \mathrm{C}$ in different gas mixtures. 